\title{
Interview with Verity Firth: commercial interests and public health policy
}

\section{Verity Firth ${ }^{\mathrm{a}, \mathrm{b}, \mathrm{e}}$ and Becky Freeman ${ }^{\mathrm{c}, \mathrm{d}}$}

a Executive Director, Social Justice, UTS, Sydney, NSW, Australia

b Former Deputy Lord Mayor of Sydney, and Member of the NSW Legislative Assembly for the Labor Party (2007-2011), serving in a range of portfolios including science and medical research, and assisting the Health Minister (cancer) and education and training

c Public Health Research \& Practice, Sax Institute, Sydney, NSW, Australia

d Prevention Research Collaboration, Sydney School of Public Health and Charles Perkins Centre, University of Sydney, NSW, Australia

e Corresponding author: Verity.Firth@uts.edu.au

\section{Article history}

Publication date: September 2019

Citation: Firth V, Freeman B. Interview with Verity Firth: commercial interests and public health policy. Public Health Res Pract. 2019;29(3):e2931918.

https://doi.org/10.17061/phrp2931918

\section{Key points}

- Politicians face intense lobbying from industry and corporate interests regarding public health reforms that impact commercial interests

- Having well-resourced 'boutique portfolios' in government that are focused on specific public health issues (e.g. cancer) gives politicians a stronger platform to promote health reforms

- Real reform involves a collective effort. The government can work alongside philanthropic organisations and others, such as academics, to win public support for new heath policy in the face of commercial opposition

- Public health advocates can take advantage of opportunities for reform when cash-strapped governments are keen to introduce visionary policies that don't require funds, but will win public favour

\section{Abstract}

Governments seeking to implement public health policy often face intense lobbying from industries vying to protect commercial interests. We spoke to Verity Firth, former Deputy Lord Mayor of Sydney and NSW Labor Minister (2007-2011), about her experiences to gain insights into ways in which governments can strike the right balance to deliver better health and social outcomes, and how public health advocates can ensure their voices are heard

\section{Q: In your experience in Australian local and state government, to what extent have you seen the influence of commercial interests play a role in shaping health and social policy? How much did health and social policy rate as a concern for political decision makers?}

A: Locally and at state level there were differences. As a councillor with the City of Sydney, it was a topic of significant concern, probably less so about the harm being caused to individuals and more about public safety and public amenity. There were big debates about issues like alcohol-free zones and strong support for safe injecting rooms. Various industry associations, such as those representing liquor licence holders, obviously lobbied hard on certain initiatives.

In State Parliament, it was still a concern, but as a minister it was closely linked to your portfolio. Ministers that were in portfolios where there was a significant impact - for example health or family and community services or housing - were much more likely to be concerned about health and social policy than if you had a portfolio like transport.

Whether ministers saw health issues as an individual problem or as a problem shaped by commercial interests depended a little bit on their politics, and their philosophical or ideological outlook.

\section{Q: How did health issues that had commercial connections rank in terms of importance for government action? For example, you did a lot in tobacco control - did you have to convince your colleagues this was a good way to go or did you receive strong support?}


A: I think it helped that we had a dedicated Minister for Cancer in NSW, and with that portfolio came the Cancer Institute ${ }^{1}$, which was separate from the Department of Health, and had a $\$ 100 \mathrm{~m}$ budget of its own. The fact that there was a resourced body that was able to concentrate on issues of cancer prevention and treatment meant that I had much more of a platform than I would otherwise have had. And I had the resource of expertise at my fingertips to provide the evidence. The way the portfolios were set up had a big impact on how I was then able to get smoking to the fore in a Cabinet debate.

$Q$ : Is having health-related portfolios with dedicated funds and staff one of the best ways for governments to combat commercial interests?

A: In a portfolio like health, which is so enormous and in which you are dealing with urgent problems every day, having something like a specific prevention body for cancer is helpful. It is otherwise hard to find airtime in the midst of the immediacy of concerns of the large-scale public health system. The idea of 'boutique portfolios' around public health issues was a good structure.

Q: Do you think political decision makers are currently striking the right balance between market freedoms and individual and community wellbeing?

A: I think Australians are more relaxed about being regulated than other countries. Although people might complain about the 'nanny state', on the whole we don't mind regulation the way the Americans do.

The issue of resources is important. If you are going to get the right balance, then you do need to resource organisations solely for public benefit. You can't have a highly resourced corporate sector and not have a reasonably resourced public benefit side.... because otherwise it will get completely skewed. However, when you combine both our bureaucratic capacity and also the capacity of some of our large-scale philanthropic organisations like the Cancer Council, we are able to achieve that balance in terms of the politicking around public health issues.

Q: In your political career, did you have to navigate a situation where a change you were working towards came under opposition from commercial interests?

A: Absolutely. We introduced the Public Health (Tobacco) Act $^{2}$ which saw a ban on the display of tobacco products and non-tobacco smoking accessories in shops, the single point of sale in larger retail outlets and the ban on smoking in cars with kids in 2009, and it was the first time l'd ever encountered the tobacco industry. They did come out and lobby us. They took other members of the Government out to lunch, they lobbied the backbench. I can't even remember particularly what their arguments were; it was a general effect that 'here we are, we're here to be heard'. The other group we really had to contend with were the retailers' associations. At least they were more upfront about what they wanted - they were saying this is a problem for us because it will impact on our sales. Both the tobacco industry and retailer lobby did their organising in local seats as well, so both those corporate interests absolutely played the political game. There was significant opposition.

\section{Q: Did the commercial interests have any chance of watering down the legislation?}

A: I don't think anyone was at all convinced by the tobacco industry's arguments. The retailers' bodies had more influence, because there was a sympathetic response in the sense that they weren't producing the cigarettes, they were just selling the cigarettes, and the small retailers included many struggling 'mum and dad' businesses. I think they got greater traction but in the end, they weren't able to water down what we did. They were able to delay the inevitable, in that we gave a longer lead-in time for smaller retailers so they had more time to adjust.

\section{Q: What lessons would you would pass on to other policy makers regarding contending with the commercial sector when trying to deliver effective public health policy?}

A: The biggest thing I learnt from introducing the Public Health (Tobacco) $\mathrm{Act}^{2}$ was the power of coalitions. We had genuine consultation and were always very transparent and open about what we intended and wanted to do. Stakeholders, including the tobacco industry and retailers, had an opportunity to make their contributions.

There was also a sense of civil society momentum. There was a group of people who wanted to make this reform happen and they were prepared to work collaboratively. The Cancer Council ran a fantastic grassroots campaign on smoking in cars with children, and they went out and got their staff and volunteers active, for example by visiting schools. We also had academics writing opinion pieces and running the evidence-based argument. These efforts strengthened my position in the Government considerably. It's a collective effort and no one politician or no one agency can do it alone when you're trying to achieve real reform.

\section{$Q$ : Was being able to demonstrate public support important?}

A: Yes. It's both the demonstration of public opinion but also the actual winning of public opinion. You're winning hearts and minds, as well as then demonstrating that the public is on your side and that is obviously powerful politically.

\section{Q: What's your advice for public health advocates to counter commercial interests and contribute to effective policy that improves health outcomes?}

A: I think to win heart and minds, you need to be careful about how you are coming across. It's about the tone that you use, and particularly in issues involving parents 
making decisions for their children, you do need to get that tone right. People get so defensive, especially if they are told they are doing something bad for their children. It is about saying we're here alongside you.

The other thing, which probably isn't said much, is that sometimes when governments don't have any money but need to do something that looks visionary, they'll do a public health initiative - legislating or regulating doesn't necessarily cost anything.

If the government feels it can win some brownie points with the electorate, for example through a policy like banning smoking in cars, then it's an easy win. As public health advocates, it's about finding those creative opportunities that can also induce behavioural change.

\section{Q: Do you think there are 'win-win' scenarios for public health and commercial interests? Is there a way for them to work collaboratively?}

A: I think commercial interests do have a sense of where something's heading, and often it would be in their interests to work more closely with public health advocates. But that takes a company that has either a sense of public purpose in and of itself, or a company that's able to read the lay of the land a bit better. For example, if you were an asbestos producer in the 1930s, and you'd been able to see what was coming, there's all sorts of things you could have done that would both protect your bottom line as well as achieve a better public health outcome.

The second thing is for commercial interests to consider is that just because it's the way something is, doesn't mean it's the way something always will be. For example, when we were first banning smoking in pubs, you would have thought that the entire pub industry was going to collapse overnight. They were really fierce lobbyists. But think about it now - it is no problem at all and I would actually argue that we've probably extended pubs' lifespan or their capacity to attract new markets well into the future, far more than their own silly short-sighted behaviour would have had them do.

I think these things can totally be a 'win win', but it does require some innovative thinking, sometimes on behalf of the commercial interests and potentially on behalf of the public health interests as well.

\section{Q: Can there be genuine partnerships between public health and commercial interests to achieve reform?}

A: When issues are negotiated between the two parties, in most cases, public health will probably get the rough end of the stick because public health will not be as well-resourced and able to pursue its interests. But that is where, I would argue, it is the role of government to step in.

\section{Peer review and provenance}

Internally peer reviewed, invited.

\section{Competing interests}

None declared.

\section{Author contributions}

The interview with VF was conducted by BF, Public Health Research \& Practice Associate Editor and a Guest Editor for Volume 29, Issue 3.

\section{References}

1. Cancer Institute NSW. History of the Cancer Institute NSW. NSW: CINSW; 23 May 2019 [cited 2019 Aug 6] Available from: www.cancer.nsw.gov.au/about-us/our-history

2. NSW Government. Public Health (Tobacco) Act 2008 No 94. Sydney: NSW Government; 2008 [cited 2019 Aug 6]. Available from: www.legislation.nsw.gov.au/acts/2008-94.pdf

\section{Copyright: (c) (i) (2) (2)}

(c) 2019 Firth and Freeman. This article is licensed under the Creative Commons Attribution-NonCommercial-ShareAlike 4.0 International Licence, which allows others to redistribute, adapt and share this work non-commercially provided they attribute the work and any adapted version of it is distributed under the same Creative Commons licence terms. See: www.creativecommons.org/licenses/by-nc-sa/4.0/ 